\title{
Post-modern 'languagers': the effects of texting by university students on three South African languages
}

\author{
Charlyn Dyers and Gaironesa Davids
}

\begin{abstract}
The present post-modern society has witnessed a growth spurt in technology, and with the development of Information and Communication Technologies (ICTs), mobile text messaging (texting) is now seen as the norm among the youth. For these late-modern languagers (Lytra and Jørgensen 2008: 5), it has become a common if not almost natural process to send and receive an SMS (Short Message Service) in different languages. Although some studies have examined the transformation and modification of the English language by mobile communication, hardly any, apart from Deumert and Masinyana (2008), have looked at how local South African languages are being reshaped and modified through this medium. Drawing on texting data from university undergraduate students, this paper examines the ways in which three South African languages Afrikaans, isiXhosa and Setswana - are used, transformed and modified through this medium of communication. It is argued here that the intense creativity displayed by these young cell phone users as they play with the multilingual resources at their disposal may lead to some form of language revitalisation for these languages.
\end{abstract}

\section{Introduction and Background}

The key issues addressed by this paper are:

- $\quad$ How are three local South African languages being used, transformed, modified and 'played with' in the texting practices of a sample of undergraduate students?

- $\quad$ Based on this data, can one argue that texting offers a space for the resemiotisation and even revitalisation of these languages?

In South Africa, as was confirmed by a recent three-country study by Porter and others (Porter 2011), mobile or cell phone ownership is high, even in low-income areas. According to the study, even in remote rural areas, up to $43 \%$ of people own cell phones, and this figure rises to $67.5 \%$ in urban areas. A study by Deumert (2009) showed that in Cape Town, $90 \%$ of the youth are phone owners. Many of them use Mxit, a popular mobile instant messaging service that claims 10 million registered users - many under the age of 18 - who send over 250 million messages daily. The network interaction data shows a highly multilingual group of teenagers who interact with one another using a variety of communication forms and language varieties. Afrikaans, isiXhosa and English, the dominant languages in this city, are all used in the digital domain, whereas face-toface communication remains isiXhosa/Afrikaans dominant with slang varieties of these 
languages showing high levels of borrowing from English (Deumert 2009, McCormick 2000). Deumert asserts that the instrumental motivations given for preferring English were consistent across Xhosa participants as English was perceived as being easy, simple, and understandable and consisting of short words, whereas isiXhosa - although used for more integrative ethno-cultural and identity reasons - was seen as difficult, complicated and deep, with long complex words.

This paper reports on the analysis of texting data obtained from 315 undergraduate students at the University of the Western Cape, South Africa from 2010 to 2011, as part of a larger research project which is investigating how digital communication technologies are re-shaping communicative practices, social interaction and identities in South Africa. This SANPAD-funded project is jointly coordinated by the Linguistics departments at the Universities of the Western Cape and Cape Town.

At the University of the Western Cape, students doing a third-year Linguistics module called Multilingualism in Society and Education submitted coursework essays which were an analysis of five sent and five received SMS (Short Messaging System) or Mxit messages on their personal cell phones. Their analysis had to include the full context for each message (sender, recipient, relation- ship, purpose, etc.) as well as a reflection on the language choices in each message. The data was then extracted from selections of these essays by post-graduate research assistants for their own research projects (cf. Davids 2010) and coded in terms of predominant language use, degree of language blending, register, slang and abbreviations. Bieswanger's classification of the shortenings used in texting (2007: 4-5) was used to identify what is commonly referred to as the 'textese' in the data. His classification includes:

- Initialisms - shortenings that consist of the first letter (or letters) of a combination of more than one word, which is then pronounced as one word. An example here would be LOL (for 'laugh out loud');

- $\quad$ Clippings - deletions of parts of a word, for example 'b' (for 'be') or 'bday' (for 'birthday');

- Contractions - combinations of two words, very similar to clippings, for example 'wana' (for 'want to');

- $\quad$ Letter/Number homophones (also called rebus writing) - letters or numbers which are pronounced like particular words are used to replace part of all of a word, for example '18' for 'late'; 'c u' for 'see you';

- Phonetic Spellings - which include all forms that are shorter than the original words they represent, e.g. 'gudnyt' for 'good night'; and finally

- Word-Value Characters - characters representing words, e.g. 'xoxo' for 'hugs and kisses' or 'mwah' to represent the sound of a kiss.

The data revealed a repertoire of local codes present in the texting messages identifiable as English, Afrikaans, isiXhosa and Setswana (four of South Africa's eleven official languages) as well as integrated blends of these languages. Language specialists in Afrikaans, isiXhosa and Setswana also provided their input on whether, in their opinion, these languages were being modified or not by the texting practices of young people. It is also important in the context of this research not only to ask how these languages are 
being modified through texting, but also what varieties form the basis for such modifications. Are changes being made to the so-called 'standard' spoken and written varieties of the languages in question, or are the informal, colloquial, oral codes, always subject to a host of influences that constantly change and revitalize such forms, being modified?

\section{Theoretical and Conceptual Framework}

This paper engages with concepts that illustrate the complex nature of communication in late modernity, where people adjust their communication in accordance with the spatial location of that communication - local, translocal, transnational or virtual. Virtual communication through a range of Information and Communication Technologies (ICTs), which include cell phone texting, has played a major role in transforming the communicative event. Through the electronic media, people confront new rules and resources for the construction of social identity and cultural belonging. Jacquemet (2005: 264) uses the term transidiomatic practices to explain and define 'the communicative practices of transnational groups that interact using different languages and communicative codes simultaneously present in a range of communicative channels, both local and distant'. Jacquemet further states that transidiomatic practices are the results of the co-presence of multilingual talk and electronic media, in contexts heavily structured by social indexicalities and semiotic codes. Thus the combination of multiple languages and simultaneous local and distant interaction is the production of a transidiomatic environment. Therefore transidiomatic practices usually produce linguistic innovations with heavy borrowing from English, but any number of other languages could be involved in these communicative recombinations, depending on the re-territorialisation needs and wants of the speakers.

Jacquemet's 'transidiomatic practices' overlaps to some extent with Blommaert, Collins and Slembrouck's (2005) notions of space which enable or disable particular multilingual language practices as well as their concept of 'truncated multilingualism', which they define as '... linguistic competencies which are organised topically on the basis of domains or specific activities' (Blommaert et al. 2005: 199). However, the concept languaging or translanguaging, which many linguists are increasingly using instead of multilingualism, perhaps best captures what young people are doing with language in mobile communication, and the ways in which 'sets of linguistic resources...are afforded for language users in different social and cultural circumstances' (Pietikäinen et al. 2008: 81) or how people use their linguistic resources '...to make meaning, transmit information and perform identities' (Creese and Blackledge 2010: 554). While Lytra and Jørgensen (2008: 5) use the term languagers to refer to 'people who use language, not $a$ language, but features of whatever ranges of languages they are exposed to in order to achieve their communicative purposes', Pennycook (2010: 85), with specific reference to languaging in urban settings, argues that the term metrolingual more accurately captures the type of interaction typical in late modernity, revealing not only hybridity and play - 'the ludic possibilities in the everyday' - but also much broader views of contexts of translingual activity.

The issue of identity is always present when one considers how languages are performed in different contexts. Pennycook (2010: 125) concurs: '...identities are not fixed and stable 
attributes of individuals, but are produced through language (and other) practices'. Perhaps the most salient comments on the issue of identity and the major focus of this paper comes from García (2010: 524, cited in Creese and Blackledge 2010: 556), who contends that multilingual speakers '...decide who they want to be and choose their language practices accordingly'. This suggests that, in the context of South Africa, young people choose which identities they want to signal through their language practices ranging from a strongly ethnic identity (I am a Xhosa and my language use will clearly show this) to an identity marked by urban sophistication and youth culture. In other words, young people show agency/'actorhood' and voice in responding to different linguistic spaces, and in the space of mobile messaging, context is crucial - who and why they are texting.

As this paper is an examination of the ways in which particular languages may be modified and adapted from the oral code to the written code through the medium of texting, the concept of resemiotisation becomes central to the study. Iedema (2003: 48) defines the concept of resemiotisation as '...how meaning makes shifts from context to context, from practice to practice, or from one stage of a practice to the next". Resemiotisation is particularly apparent in the different shortening strategies that have to be learned by texters in order to be able to send short yet comprehensible messages owing to the limited character space (about 160 characters) on the screens of mobile phones (Crystal 2001: 229). According to Prior and Hengst (2010: 143) resemiotisation 'focuses on practices enabling semiotic phenomena to shift from one practice context to another', with such shifts removing the interaction from the 'here and now' particulars into domains where knowledge of such specifics is either assumed or purposefully backgrounded and rendered non-negotiable. Young people in particular have shown great aptitude for using new forms of expression and adapting to virtual spaces for meaningmaking. Their texting messages are marked by great creativity and language play, reminiscent of Wittgenstein's insistence that 'language games are a form of life' and at the heart of the social construction of meaning (Wittgenstein 1988, cited in Williams 2010: 161). As Pennycook (2010: 8) asserts, 'language is a product of social action, not a tool to be used'. Language(s) thus get produced by practices like texting - activities that are repeated and thus become norms, which in turn are also subject to new practices.

A number of important studies on texting has been done in South Africa. Vosloo (2009) sees it as an emerging language register in its own right - 'the written lingua franca of many youth today', while Freudenberg (2009) asserts that texting gives adolescents a medium that encourages them to explore and play about with the use of their language. A study by Deumert and Masinyana (2008: 117) on the patterns of language use in mobile messaging among young isiXhosa speakers, found that English is the preferred code for most of them, and that the majority of their messages conformed largely to they describe as 'a globalised SMS English norm'. Nevertheless, the messages also displayed local features both in terms of form and content (Deumert and Masinyana 2008). They further suggest that choosing isiXhosa and not abbreviating it comes at a direct cost (around 80 cents per message) to the bilingual user, and generally isiXhosa speakers reacted with puzzlement to the very idea of abbreviated SMS in isiXhosa (Deumert and Masinyana 2008). Their findings show that young isiXhosa home language speakers prefer using 
English in SMS communication since it is not easy to abbreviate isiXhosa, which occurs most commonly in code-mixed messages.

In contrast to their Xhosa compatriots, a study by Weimers (2008: 16) found that Afrikaans speaking adolescents preferred to text in the language of the person they were contacting. This study also suggested that predominantly Afrikaans texting did not use the same features of messaging as predominantly English texting. In particular, the Afrikaans-speaking users were less likely to use rebus writing, as very few letter/number words in Afrikaans have a similar phonetic sound. For instance, in English, the pronunciation of four is the same as that of for, and therefore the number 4 can be used to replace the word for when trying to save space in an SMS. However, in Afrikaans, the pronunciation of vier differs significantly from that of vir (for), and therefore the number 4 cannot be used instead of the Afrikaans word for 'for' (Freudenberg 2009).

While studies on texting in Setswana were not found by the authors at the time of writing this paper, there is nevertheless a good deal of commentary on the issue by listeners to a popular youth radio station in Botswana called Yarona FM as a result of a blog posted by radio commentator Phenyo Moroka. In this blog, he expressed his concern at his own lack of Setswana in his daily texting to his wife, which takes place solely in English. Comments ranged from agreement that Setswana texting was far too expensive, to strong criticism about the exclusive use of English being indicative of a lack of pride in a Setswana identity. However, Pennycook (2010: 86-7) contends that we should not be thinking about English as 'a describable entity' if we orientate our thinking towards language as a local practice. Instead, English should be seen as '...embedded in local practices' and he further suggests that 'English has always been local'. This is certainly the case in South Africa, where English is the dominant language in business and much of public life, as well as the dominant language of instruction for most children, frequently from as early as Grade 4 (Casale and Posel 2010: 58). The embedding of English in local practices is clearly visible in the languaging practices of the student respondents in this study. In line with the definition of languaging provided above by Pietikäinen et al. (2008: 81), these young texters draw on all the linguistic resources available in their environment in order to fulfil their communicative purposes.

\section{Findings}

The data is presented in three tables to represent each of the predominant local languages found in the corpus, namely Afrikaans, isiXhosa and Setswana, which are blended with English to a greater or lesser degree. These languages are shown in italics. The first column contains the original message which is transcribed fully in the second column. A translation into English is provided in the third column, and all creative features of 'textese' are provided and explained in the last column. Each table is followed by a discussion of its specific findings.

\section{Discussion of Table 1}

These messages clearly indicate that more than one set of linguistic and socio-cultural knowledge is present in the respondents, and therefore correspond with the definitions of the concept of languaging provided above. 
Extract 1 is an example of a message that contains English and Afrikaans, thus from a tradition- ally monolingual perspective we would say that code-switching occurred because the switch occurred from one language to the next in two different sentences. However, the concepts of code-switching and mixing are based on the perspective of languages as autonomous, bounded systems, whereas these messages are hybrid and have no boundaries. Thus, we note a range of shortenings like 'j' (jy - you), 'jo' (jou - you), 'ni' (nie - don't) and ' $t$ ' (te - to) where letters have been omitted to form shorter versions of the same words without losing their meaning. The word 'wiet' (weet - know) captures the way in which the word is locally pronounced in the variety of Afrikaans known as Kaaps, with the diphthong /ı/ of the standard Afrikaans word 'weet' shortened to the /I/ of 'wiet'. This is proof of the diversity and hybridity of the texting in these examples, as standard and non-standard language codes are used within the same message.

Table 1: Predominantly Afrikaans data

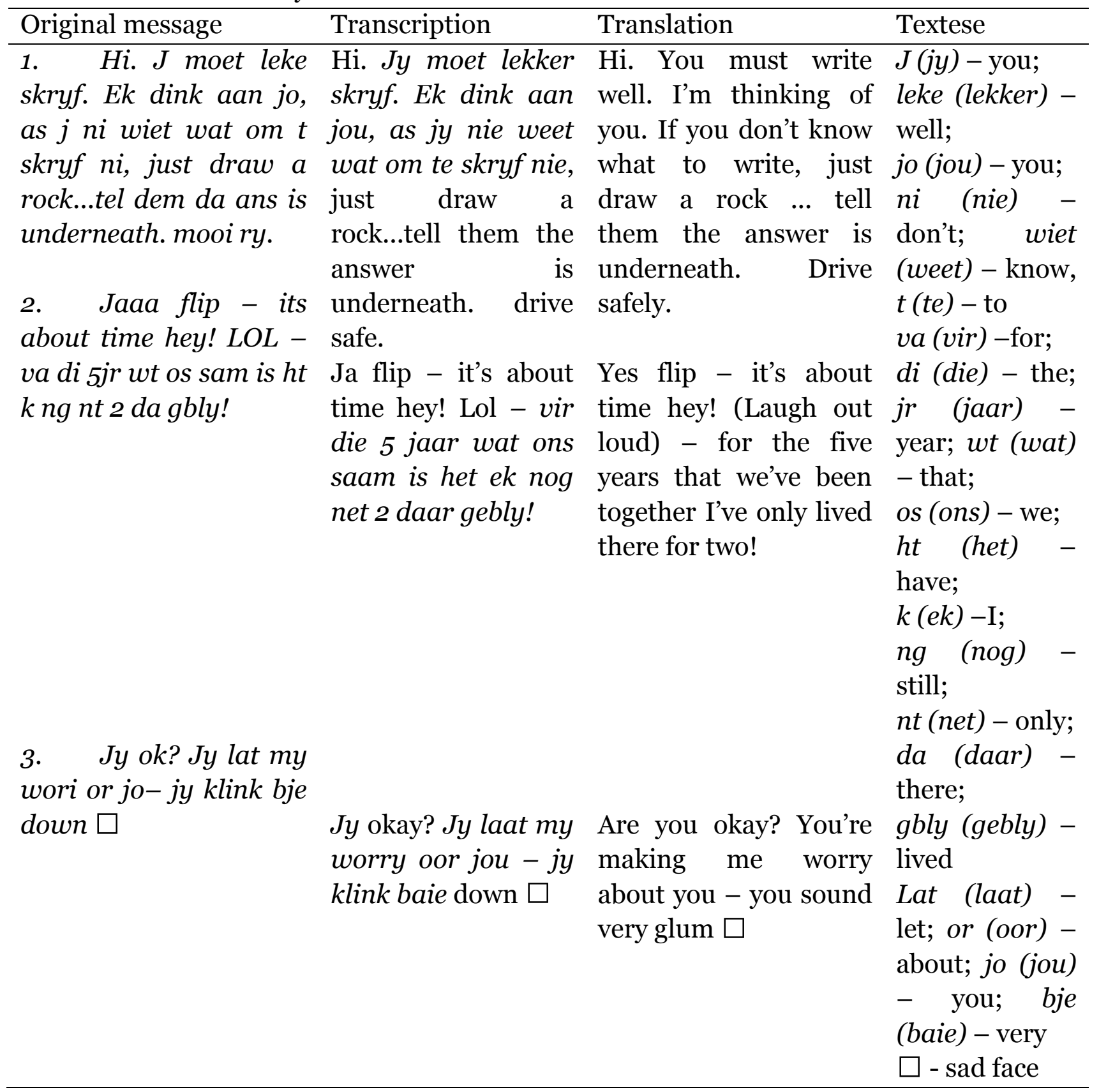


Extract 2 is another example of local languaging, with its blend of English and Afrikaans words and expressions, unconventional spellings and contractions. The first word of the text is 'Jaaa' which is normally spelled ' $\mathrm{ja}$ ' (yes); in this case two extra letters ' $a$ ' were added to the word in order to capture how the word is usually uttered when the speaker is in a more contemplative frame of mind. The word 'flip' is a reduction of the slang phrase 'flipping heck' used to indicate surprise, shock or irritation. And although Afrikaans abbreviations for $L O L$ (laugh out loud) exist, it is used here in preference to the Afrikaans LMK (lag my klaar), and can be taken as an indication of the ease with which these young texters move between languages. A range of contractions like 'va' (vir - for), 'di' (die the), 'jr' (jaar - year), ' $w t^{\prime}$ ' (wat - what) and 'os' (ons - us) is also present in this extract. Within these examples both vowels and consonants have been omitted in order to save space and shorten the message. This highlights the diversity of the language usage as well as the hybrid nature of the communication.

Extract 3, while shorter than the previous two messages, also demonstrates many of the characteristics of texting, e.g. use of shortenings like 'lat' (laat - let), 'or' (oor - about), 'jo' (jou - you) and 'bje' (baie - very), which is another example of how the oral code is captured in writing, as it mimics the actual pronunciation of the word 'baie'. In addition, this message has emotion-laden words like 'wori' and 'down' and is multimodal in nature, with feelings portrayed by a sad face for emphasis ( $\square$ ). This shows that texting goes beyond words and involves more than one mode of communication.

\section{Discussion of Table 2}

In their study, Deumert and Masinyana (2008) found that isiXhosa messages differ from English language messages in that they contain no abbreviated material, non-standard spelling or paralinguistic restitutions and therefore violate the sociolinguistic maxims of texting. In addition, many young isiXhosa speakers appear to prefer to use mainly English in their texting. However, as can be seen in Table 2, the use of isiXhosa was quite commonplace and these messages also made use of key features of texting like contractions and abbreviations.

Table 2: Predominantly isiXhosa data

\begin{tabular}{|c|c|c|c|}
\hline Original message & Transcription & Translation & Textese \\
\hline $\begin{array}{l}\text { 4. Eita my broer, } \\
\text { adna } \\
\text { waneleyo moya } \\
\text { kodwa ke ndlapha } \\
\text { eMfuleni ngk bt } \\
\text { remeba I'm nt yo } \\
\text { friend my friend... } \\
\text { KFC. ;-) }\end{array}$ & $\begin{array}{l}\text { Eita my brother, } \\
\text { andinamoya } \\
\text { waneleyo } \\
\text { kodwa ke ndilapha } \\
\text { eMfuleni ngoku but } \\
\text { remember I'm not } \\
\text { your friend my } \\
\text { friend...KFC;-) }\end{array}$ & $\begin{array}{l}\text { Hello my brother, } \\
\text { I don't have } \\
\text { enough airtime } \\
\text { Jola but I am } \\
\text { here at Mfuleni } \\
\text { now } \\
\text { remember I'm } \\
\text { not your friend } \\
\text { my friend... laugh } \\
\text { out loud;-) }\end{array}$ & $\begin{array}{l}\text { Adna moya } \\
\text { (andinamoya) - I } \\
\text { don't have; } \\
\text { ndlapha(ndilapha) - I } \\
\text { am here); } \\
\text { Ngk (ngoku) - now; } \\
\text { KFC: abbreviation for } \\
\text { khawufane ucinge } \\
\text { (LOL: laugh out loud); } \\
\text {;-): smiley face; } \\
\text { English shortenings: bt } \\
\text { - but; rememba - } \\
\text { remember; nt - not. } \\
\text { Ukundibna }\end{array}$ \\
\hline
\end{tabular}


5. $\quad$ Do $\quad u \quad$ think Do u think ungakwaz

ungakwaz

ukundibna

apha

eksen $n$ thn sithethe

later on I mic u, plz send a colbek if yes.

6. Mtase

this

\section{year ndidicider} ukubuyela

esikolweni coz asikho ispan esigrand and ndidikiwe

kukuphangela kule ndawo ndiphangela kuyo. ukundibona

apha

ekuseni and then sithethe later on I miss you, please send a call back if yes.

Do you think you can manage to see me here early morning then we can speak later on I miss you, please send a call back if yes.

Mntase this year ndidicider ukubuyela esikolweni because asikho ispan esigrand and ndidikiwe kukuphangela kule ndawo ndiphangela kuyo.

Cousin this year I decided to go back to school because there are no good jobs and I am tired of working where I am working. (ukundibona) - to be able to see me Eksen (ekuseni) - early morning.

English shortenings: plz - please; colbek call back.
Mtase (mntase) cousin; 'Xhosalisation' of English loanwords: Ndidicider - I decided; Esigrand - good; English shortening: coz - because.

For example, in extract 4, the following word/phrasal contractions occur: 'andinamoya' (I don't have) was contracted to form 'adna moya' by omitting the letters ' $n$ ' and ' $i$ '; 'ndilapha' (I am here) was constricted to form 'ndapha' by omitting the letters ' $i$ ' and ' $l$ ' and lastly, the word ' $n g o k u$ ' (now) was contracted to form ' $n g k$ ' by omitting the vowels 'o' and ' $u$ '. There is also an isiXhosa alternative for $L O L$ (laugh out loud), which the texter here has translated into the abbreviation $K F C$, followed by a 'smiley face' created with punctuation marks. In addition, while the first part of extract 4 is mainly in isiXhosa apart from the Afrikaans 'my broer' (my brother), which is a very common colloquial salutation in South Africa, the last part is in English textese, using clippings e.g. $b t$ for 'but' and phonetic spelling, e.g.'rememba' for 'remember'. As with the predominantly Afrikaans data in Table 1, a creative yet highly normative blending of languages can also be seen in these examples.

Extract 5, which opens and ends in English textese, continues the pattern of word contractions without any loss of meaning to the intended recipient, e.g. 'ukundibna' drops the vowel 'o' from the original 'ukundibona' (to be able to see me), and the much shorter 'eksen' to replace 'ekuseni' (in the early morning). The message contains two interesting examples of South African English textese, such as the phonetic spelling of 'call back' which here becomes 'colbek' and 'mic' for the word 'miss'. We also note how this extract uses the English collocation ' $n$ thn' (and then) within a predominantly isiXhosa message instead of the much longer isiXhosa version of 'ukuze sifumane'.

Extract 6 is written almost entirely in isiXhosa except for the English phrase 'this year' and the two conjunctions 'coz' and 'and'. Another interesting feature here is the incorporation and 'Xhosalisation' of the English loanwords 'decide' in the phrases ndidicider (I decided) and 'grand' in 'esigrand'. Paxton and Tyam (2010: 255) note that the use of words integrated and accepted into isiXhosa is described colloquially as 'Xhosalising' and several examples of these were present in the predominantly isiXhosa corpus. Another contraction used in this message is ' $m$ tase' to replace 
Like the predominantly Afrikaans examples, these three texts showcase not only the hybridity of texting but also the flexibility associated with it. They further show that abbreviations, phonological approximations and non-standard spellings are common to predominantly isiXhosa texting. It is, however, an entirely different case when the much smaller corpus of Setswana-English data is considered, as can be seen from the extracts in Table 3.

\section{Discussion of Table 3}

In the case of the Setswana-English data, there was no need to transcribe the original messages because, apart from some English shortenings like 'coz' in extract 10, rebus writing like '2nyt' and commonly-used symbols like @, the Setswana words and phrases in these messages were not shortened in any way to suit the maxims of textese. While these texters have largely relied on English to convey their messages, they nevertheless signal their Setswana identity by incorpo- rating Setswana words and phrases in each message. In these extracts a much clearer boundary or traditional code-switching can be seen in the use of the two languages, and there is only one example (in extract 9) of an English word ('go') being incorporated into a Setswana phrase. While these findings may simply reflect the smaller size of the Setswana data when compared to the Afrikaans and isiXhosa data, it also corresponds with what little research there is available on texting in Setswana. In terms of modification through this medium, the Setswana data used here, according to the Setswana language practitioner used as informant, shows no modification from standard spoken Setswana. However, it is significant that the specific Setswana words and phrases in these messages actually use fewer characters than their English equivalents. Therefore, apart from signalling a Setswana identity, it is cheaper to use e.g. dingalo, rather than 'I'm struggling' (extract 7), or ga o arabe mogala rather than 'you are not answering the phone' (extract 10).

\section{Conclusions}

Although the writers have commented on the integrated linguistic competence of the students as evidenced by their texting data, it is necessary within the context of this paper to answer questions on the modifications made to specific local languages individually. From the existing data, the following conclusions can be drawn:

The data suggests that texting is a means for young people to capture the informal oral code orthographically - i.e. the students providing the messages 'write as they speak' but at the same time are particularly creative in making these oral messages fit into the medium of texting.

Table 3: Setswana-English data (Setswana in italics)

\begin{tabular}{lllll}
\hline Original message & Transcription & Translation & Textese \\
\hline $7 . \quad$ Hello mama & Not needed & Hello mama finished & None \\
finished registering and & registering and & \\
I'm very tired. I have & I'm very tired. I tried & \\
tried looking for a job but & looking for a job but it's \\
dingalo. & tiring. & \\
\hline
\end{tabular}


Not needed

8. Lets meet

@khwest for drinks and

besides kena le lebaka ke Not needed sa go bone.

9. Yeah!! I think i should wait and see how it works out...ga o battle go tswa 2nyt.

Not needed

10. Hey ma fwend!! Tried calling you earlier ga o arabe mogala wanted to tell you that you should get your dancing shoes coz im getting married next year.
Lets meet at Khwest for drinks and besides it's been a while since I last saw you. 2nyt Yeah!! I think I should wait tonight and see

how it works out...don't you want to go out tonight.

Hey my friend!! Tried calling you earlier you are not answering the phone wanted to tell you that you should get your dancing shoes because I'm getting I'm married next year. 
This brings us to the issue of the possible revitalisation of these local languages through ongoing modification. Over time, the resemiotised forms in these texting practices may, as a result of constant use, become '... sedimented through repeated acts of sameness' (Pennycook 2010). In other words, they may become fully incorporated in everyday spoken and even written practices, modifying and revitalising existing spellings and sentence constructions in these languages, as well as creating novel words, abbreviations and expressions. All varieties in constant use (with strong linguistic vitality) are subject to on-going modification in the late-modern, globalised world, although urban varieties show the strongest changes as a result of the intense heteroglossia (Bahktin 1981) in such spaces. According to Bhatt (2008: 182):

The third space - linguistic hybridity - gives rise to possibilities for new meanings and at the same time presents a mechanism to negotiate and navigate between a global identity and local practices. It also allows its consumers (readers) to (re-) position themselves with regard to new community practices of speaking and writing.

Williams (2010: 92-3) contends that globalisation and the rise of the knowledge economy have opened up new spaces 'for a reconsideration of the relationship between languages'. He also cites Graddol (2000) who argues that while many of the world's minority languages are in danger of disappearing, there will also be a new process of linguistic hybridisation that will generate new varieties of language. Instead, therefore, of the weak, policy-driven attempts to protect individual languages as bounded entities, South Africa should be addressing the issues of linguistic hybridisation and the integrated competence of languagers as central components of language education. Further research is needed on how these forms can best be exploited in the classroom, but of course the teaching of standard, prestige varieties cannot be discontinued if students are to gain access to higher education and careers in which such varieties are economic and social capital. However, standard varieties should never be 'finally fixed' but should always be open to the influences of linguistic innovation and hybridity.

Acknowledgements - Our sincere thanks to language specialists Ntombizodwa Dlayedwa (isiXhosa), Frank Hendricks (Afrikaans) and Naomi Molokomme (Setswana) for their input to this paper. This research was made possible with funding from the National Research Foundation. 


\section{References}

Bakhtin M. 1981. The dialogic imagination. Four essays. Holquist M (ed.); translated by Emerson C, Holquist M. Austin: University of Texas Press.

Bhatt RM. 2008. In other words: Language mixing, identity representations, and third space. Journal of Sociolinguistics, 12: 177-200.

Bieswanger M. 2007. 2 abbrevi8 or not 2 abbrevi8: a contrastive analysis of different shortening strategies in English and German texts. SALSA (Symposium about Language and Society) XIV proceedings, 2006. Hallett T, Floyd S, Oshima S, Shields A. (eds) Austin, Texas.

Blommaert J. 2010. A Sociolinguistics of Globalization. Cambridge: Cambridge University Press.

Blommaert J, Collins J, Slembrouck S. 2005. Spaces of multilingualism. Language and Communication. Cambridge: Cambridge University Press. 25: 197-216.

Casale D, Posel D. 2010. Mind your Language: the Benefits of English Proficiency in the Labour Market. In: 2010 Transformation Audit: Vision or Vacuum? - Governing the South African Economy. Cape Town: Institute for Justice and Reconciliation. pp 58-65.

Creese A, Blackledge A. 2010. Towards a sociolinguistics of superdiversity. DOI 10.1007/s11618-010-0157y. Published online 15.12.2010. VS Verlag fur Sozialwissenschaften, 449-573. [Accessed 20 February 2013].

Crystal D. 2001. Language and the Internet. Cambridge: Cambridge University Press.

Davids G. 2010. Mobile Communication: An investigation into the transformation and reshaping of three local South African languages via cell phone messaging. BA Honours Research Essay, Department of Linguistics, University of the Western Cape, South Africa.

Deumert A. 2009. Klk cc...Supporting Indigenous Literacies in the Digital Space. Cape Town: John Benjamins Publishing.

Deumert A, Masinyana SO. 2008. Mobile language choices - The use of English and isiXhosa in text messages (SMS): Evidence from a bilingual South African sample. Cape Town: John Benjamins Publishing. English World-Wide. 29: 117-147.

Freudenberg K. 2009. Investigating the impact of SMS speak on the written work of English first language and English second language high school learners. Master's Thesis, Division of Philosophy, Stellenbosch University, South Africa.

García O. 2010. Languaging and ethnifying. In: Fishman J, García O. (eds) Handbook of language and ethnicity: Disciplinary and regional perspectives (2nd edn, vol. 1). New York: Oxford University Press. pp 519-535.

Graddol D. 2000. The Future of English? London: British Council.

Iedema R. 2003. Multimodality, resemiotisation: Extending the analysis of discourse as multi-semiotic practice. Visual Communication 2: 29-57.

Jacquemet M. 2005. Transidiomatic practices: Language and power in the age of globalisation. Language and Communication. 25: 257-278.

Jørgensen JN. 2008. Polylingual Languaging Around and Among Children and Adolescents. International Journal of Multilingualism. London: Routledge. 5: 161176.

Lytra V, Jørgensen JN. (eds) 2008. Multilingualism and Identities across Contexts. Cross disciplinary perspectives on Turkish-speaking youth in Europe. Copenhagen 
Studies in Bilingualism volume 45. Faculty of the Humanities, University of Copenhagen, Denmark.

McCormick K. 2000. Language in Cape Town's District Six. Oxford: Oxford University Press.

Paxton M, Tyam N. 2010. Xhosalising English? Negotiating meaning and identity in Economics. South African Linguistics and Applied Language Studies 28: 247-257.

Pennycook A. 2010. Language as a Local Practice. New York: Routledge.

Pietikäinen S, Alanen R, Dufva H, Kalaja P, Leppänen S, Pitkänen-Huhta A. 2008. Languaging in Ultima Thule: Multilingualism in the Life of a Sami boy. International Journal of Multilingualism 5:79-99.

Porter G. 2011. Young people, mobile phones and virtual mobility - a three-country study. Seminar presented in the Department of Anthropology and Sociology, University of the Western Cape, 20 April 2011.

Prior P, Hengst J (eds). 2010. Exploring Semiotic remediation as discourse practice. Basingstoke, UK: Palgrave Macmillan.

Vosloo S. 2009. The effects of texting on literacy: Modern scourge or opportunity? An issue paper from the Shuttleworth Foundation. Shuttleworth Foundation.

Weimers M. 2008. 2 Mix or nt 2 MIX? (Dats $d$ kwestion): The effort of instant messaging on Afrikaans speaking adolescents in South Africa. Undergraduate research report, Division of Speech, Language and Hearing Therapy, Stellenbosch University, South Africa.

Williams G. 2010. The Knowledge Economy, Language and Culture. Bristol: Multilingual Matters.

Wittgenstein L. 1988. Tractatus Logico-Philosophicus. London: Routledge. 